\title{
Integrin activation states and eosinophil recruitment in asthma
}

\author{
Mats W. Johansson ${ }^{1}$ and Deane F. Mosher ${ }^{1,2}$ \\ ${ }^{1}$ Department of Biomolecular Chemistry, University of Wisconsin, Madison, WI, USA \\ ${ }^{2}$ Department of Medicine, University of Wisconsin, Madison, WI, USA
}

\section{Edited by:}

Amr El-Shazly, Liege University

Hospital, Belgium

Reviewed by:

Amr El-Shazly, Liege University Hospital, Belgium

Jane Da Silva, University of Southern

Santa Catarina, Brazil

*Correspondence:

Mats W. Johansson, Department of Biomolecular Chemistry, University of Wisconsin, 4285A Medical Sciences Center, 1300 University Avenue, Madison, WI 53706, USA.

e-mail:mwjohansson@wisc.edu
Eosinophil arrest and recruitment to the airway in asthma are mediated, at least in part, by integrins. Eosinophils express $\alpha_{4} \beta_{1}, \alpha_{6} \beta_{1}, \alpha_{\llcorner} \beta_{2}, \alpha_{M} \beta_{2}, \alpha_{X} \beta_{2}, \alpha_{D} \beta_{2}$, and $\alpha_{4} \beta_{7}$ integrins, which interact with counter-receptors on other cells or ligands in the extracellular matrix. Whether a given integrin-ligand pair mediates cell adhesion and migration depends on the activation state of the integrin. Integrins exist in an inactive bent, an intermediate-activity extended closed, and a high-activity extended open conformation. Integrin activation states can be monitored by conformation-specific monoclonal antibodies (mAbs). Studies in mice indicate that both $\beta_{1}$ and $\beta_{2}$ integrins mediate eosinophil recruitment to the lung. In vitro studies indicate that $\alpha_{4} \beta_{1}$ and $\alpha_{M} \beta_{2}$ are the principal integrins mediating eosinophil adhesion, including to vascular cell adhesion molecule- 1 and the novel $\alpha_{M} \beta_{2}$ ligand periostin. In vivo, blood eosinophils have intermediate-activity $\beta_{1}$ integrins, as judged by mAb N29, apparently resulting from eosinophil binding of $P$-selectin on the surface of activated platelets, and have a proportion of their $\beta_{2}$ integrins in the intermediate conformation, as judged by mAb KIM-127, apparently due to exposure to low concentrations of interleukin-5 (IL-5). Airway eosinophils recovered by bronchoalveolar lavage (BAL) after segmental antigen challenge have high-activity $\beta_{1}$ integrins and high-activity $\alpha_{M} \beta_{2}$ that does not require IL-5. Here we review information on how the activation states of eosinophil $\beta_{1}$ and $\beta_{2}$ integrins correlate with measurements of eosinophil recruitment and pulmonary function in asthma. Blood eosinophil N29 reactivity is associated with decreased lung function under various circumstances in non-severe asthma and KIM-127 with BAL eosinophil numbers, indicating that intermediate-activity $\alpha_{4} \beta_{1}$ and $\alpha_{M} \beta_{2}$ of blood eosinophils are important for eosinophil arrest and consequently for recruitment and aspects of asthma.

Keywords: eosinophils, integrins, adhesion, asthma, inflammation

\section{INTRODUCTION}

Eosinophilic airway inflammation is frequent pattern in different phenotypes or endotypes of asthma (Busse and Lemanske, 2001; Scott and Wardlaw, 2006; Simpson et al., 2006; Anderson, 2008; Haldar et al., 2008; Hogan et al., 2008; Blanchard and Rothenberg, 2009; Woodruff et al., 2009; Hastie et al., 2010; Lee et al., 2010; Moore et al., 2010; Kita, 2011; Lotvall et al., 2011; Siroux et al., 2011; Wang et al., 2011; Agache et al., 2012; Wenzel, 2012; Rosenberg et al., 2013). Airway eosinophilia is associated with exacerbations (Haldar et al., 2009; Nair et al., 2009; Busse et al., 2010; Pavord et al., 2012; Robinson, 2013) and has been suggested to play a role in airway remodeling (Flood-Page et al., 2003; Kay et al., 2004; Wills-Karp and Karp, 2004; Busse et al., 2010; Robinson, 2013). Arrest of eosinophils in vessels and their extravasation into the airway wall and through the bronchial tissue and epithelium to the airway lumen are mediated in part by the integrin family of cell adhesion receptors (Banerjee et al., 2007, 2009; Rosenberg et al., 2007; Barthel et al., 2008).

Integrins are heterodimers of $\alpha$ and $\beta$ subunits (Hynes, 1987; Ruoslahti, 1991). Each integrin interacts or potentially interacts with counter-receptors on other cells or ligands deposited as part of the extracellular matrix (ECM) (Humphries et al., 2006). Whether a given pair of integrin and counter-receptor/ECM ligand participates in cell adhesion and migration depends on the cell-surface density of the integrin, the density of the ligand, and the activation state of the integrin (Huttenlocher et al., 1996; Palecek et al., 1997; Askari et al., 2009). Integrins exist in three major conformations, including an inactive or low-activity, bent conformation; an intermediate-activity, extended, "closed" conformation with a partially occluded ligand-binding "head piece"; and a high-activity, extended, "open" conformation with a more open "head piece," swung-out hybrid domain, and separation of the "legs" of the two subunits (Figure 1) (Luo and Springer, 2006; Luo et al., 2007; Evans et al., 2009; Hogg et al., 2011; Margadant et al., 2011). The activation states of integrins can be monitored by conformation-specific monoclonal antibodies (mAbs) (Table 1; Figure 1) (Humphries, 2004; Byron et al., 2009). Integrins are activated through so-called "inside-out" signaling by signals triggered through other receptors, including G-protein coupled receptors (GPCRs) for chemokines, and mediated by cytoplasmic factors including talin and kindlins that bind the cytoplasmic tail of integrin $\beta$ subunits (Evans et al., 2009; Harburger and Calderwood, 

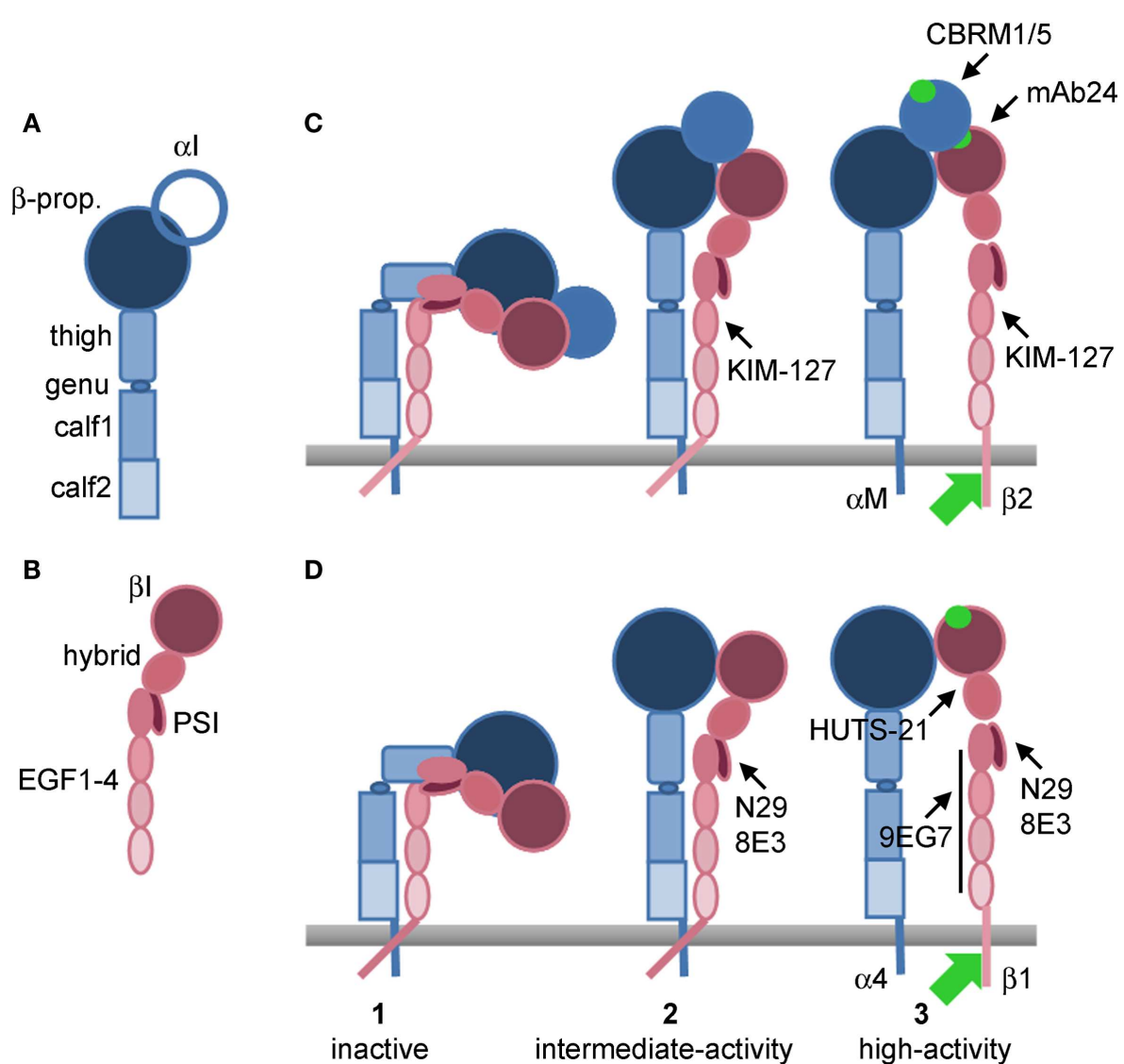

FIGURE 1 | Models of integrin conformations with epitopes for activation-sensitive mAbs. (A) Domains of an integrin a subunit. (B) Domains of an integrin $\beta$ subunit. (C) Conformational changes during activation of $\alpha_{M} \beta_{2}$ that uncover epitopes for anti- $\beta_{2}$ KIM-127 and mAb24, and anti- $\alpha_{M}$ CBRM1/5. (D) Conformational changes during activation of $\alpha_{4} \beta_{1}$ that uncover epitopes for anti- $\beta_{1}$ N29, 8E3, HUTS-21, and 9EG7. (1) Inactive, bent conformations; (2) intermediate-activity, extended, closed conformations; (3) high-activity, extended, open conformations. In (C) conformation 1 of $\alpha_{M} \beta_{2}$ is presumably KIM-127-/mAb24-/CBRM1/5-, conformation 2 KIM-127+/mAb24-/CBRM1/5-, and conformation 3
KIM-127+/mAb24+/CBRM1/5+. In (D) conformation 1 of $\alpha_{4} \beta_{1}$ is presumably N29-/8E3-/HUTS-21-/9EG7-, conformation 2 N29+/8E3+/HUTS-21-/ 9EG7-, and conformation 3 N29+/8E3+/HUTS-21+/9EG7+. Green circle, ligand-binding site in $\alpha$ d domain in (C) or $\beta \mid$ domain in (D), or binding site in $\beta \mid$ domain for activated $\alpha$ l domain in (C). Green arrow, cytoplasmic proteins, including talin and kindlins, that bind the $\beta$ integrin subunit tail and mediate activation. $\beta$-prop., $\beta$-propeller domain; EGF, integrin epidermal growth factor-like domain; PSI, plexin-semaphorin-integrin domain. Based on (Luo and Springer, 2006; Luo et al., 2007; Barthel et al., 2008; Evans et al., 2009; Hogg et al., 2011).
2009; Shattil et al., 2010; Hogg et al., 2011; Margadant et al., 2011). Engagement of integrins by ligands, in turn, can activate cytoplasmic signaling pathways, “outside-in” signaling (Harburger and Calderwood, 2009; Margadant et al., 2011).

\section{EOSINOPHIL INTEGRINS}

We briefly discuss the eosinophil integrin repertoire and their counter-receptors, ligands or potential ligands here, focusing on recent novel information. For a more extensive overview over eosinophil integrins and their ligands, including potential functions of the integrins that are not the focus here, we refer the reader to our previous review (Barthel et al., 2008). Eosinophils possess a unique repertoire of seven integrins, $\alpha_{4} \beta_{1}, \alpha_{6} \beta_{1}, \alpha_{L} \beta_{2}$, $\alpha_{M} \beta_{2}, \alpha_{X} \beta_{2}, \alpha_{D} \beta_{2}$, and $\alpha_{4} \beta_{7}$ integrins (Barthel et al., 2008; Hogan et al., 2008). Eosinophil integrins have the potential to mediate adhesion and migration on vascular cell adhesion molecule- 1 (VCAM-1) via $\alpha_{4} \beta_{1}, \alpha_{M} \beta_{2}, \alpha_{X} \beta_{2}, \alpha_{D} \beta_{2}$, and $\alpha_{4} \beta_{7}$; intercellular adhesion molecule-1 (ICAM-1) via $\alpha_{L} \beta_{2}$ and $\alpha_{M} \beta_{2}$; laminin via $\alpha_{6} \beta_{1}$; fibrinogen/fibrin via $\alpha_{M} \beta_{2}$ and $\alpha_{X} \beta_{2}$; and vitronectin via $\alpha_{M} \beta_{2}$ (Barthel et al., 2008). In our hands, purified human blood eosinophils, in the absence of added soluble stimulus, adhere in vitro specifically only to VCAM-1, primarily via $\alpha_{4} \beta_{1}$. Eosinophils from some subjects and eosinophils under flow conditions also adhere to VCAM-1 via $\alpha_{M} \beta_{2}$ (Barthel et al., 2006a,b). Purified airway eosinophils, recovered by bronchoalveolar lavage (BAL) $48 \mathrm{~h}$ after segmental lung antigen challenge (a model of allergic airway inflammation), or blood eosinophils stimulated with interleukin-5 (IL-5), adhere specifically to VCAM-1 via $\alpha_{4} \beta_{1}$ and $\alpha_{M} \beta_{2}$, and to ICAM-1, fibrinogen, and vitronectin via $\alpha_{M} \beta_{2}$ (Barthel et al., 2006b). In addition, we recently discovered that blood eosinophils stimulated with IL-5, IL-3, or granulocyte macrophage-colony stimulating factor (GM-CSF) specifically adhere to and migrate on periostin via $\alpha_{M} \beta_{2}$ (Johansson et al., 2013b). Periostin is an ECM protein upregulated by T helper cell 
Table 1 | Some activation-sensitive anti-integrin antibodies.

\begin{tabular}{|c|c|c|c|c|}
\hline Antibody & Integrin subunit & Epitope location & Recognized conformation(s) & Reference \\
\hline N29 & $\beta_{1}$ & PSI domain & Intermediate- and high-activity & $\begin{array}{l}\text { Wilkins et al. (1996), Ni et al. (1998), Mould et al. } \\
\text { (2005), Barthel et al. (2008), Byron et al. (2009) }\end{array}$ \\
\hline 8E3 & $\beta_{1}$ & PSI domain & Intermediate- and high-activity & $\begin{array}{l}\text { Coe et al. (2001), Mould et al. (2005), Barthel et al. } \\
\text { (2008), Byron et al. (2009) }\end{array}$ \\
\hline HUTS-21 & $\beta_{1}$ & Hybrid domain & High-activity & Luque et al. (1996), Barthel et al. (2008) \\
\hline $9 E G 7$ & $\beta_{1}$ & EGF-like domains & High-activity & $\begin{array}{l}\text { Lenter et al. (1993), Bazzoni et al. (1995), Barthel } \\
\text { et al. (2008), Byron et al. (2009) }\end{array}$ \\
\hline KIM-127 & $\beta_{2}$ & 2nd EGF-like domain & Intermediate- and high-activity & $\begin{array}{l}\text { Robinson et al. (1992), Beglova et al. (2002), Byron } \\
\text { et al. (2009), Evans et al. (2009) }\end{array}$ \\
\hline mAb24 & $\beta_{2}$ & I domain & High-activity & $\begin{array}{l}\text { Dransfield and Hogg (1989), Leitinger and Hogg } \\
\text { (2000), Lu et al. (2001), Byron et al. (2009), Evans } \\
\text { et al. (2009) }\end{array}$ \\
\hline CBRM1/5 & $\alpha_{M}$ & I domain & High-activity & Oxvig et al. (1999), Byron et al. (2009) \\
\hline
\end{tabular}

EGF, epidermal growth factor; PSI, plexin-semaphorin-integrin.

type 2 (Th2) cytokines in bronchial epithelial cells and lung fibroblasts and is deposited in patients with asthma and atopic dermatitis, as well as in animal models of asthma and allergic skin inflammation (Yuyama et al., 2002; Takayama et al., 2006; Hayashi et al., 2007; Woodruff et al., 2007; Masuoka et al., 2012). Mice lacking periostin respond to lung antigen challenge with significantly decreased number of eosinophils in the lung and have reduced allergic skin inflammation (Blanchard et al., 2008; Bentley et al., 2012; Masuoka et al., 2012), thus implicating periostin as a ligand in eosinophil recruitment and retention in allergy and asthma. Further, studies of $\beta_{2}$-deficient and conditionally $\alpha_{4}$-deficient mice indicate that both $\beta_{2}$ and $\alpha_{4}$, presumably principally $\alpha_{4} \beta_{1}$, integrins mediate trafficking of eosinophils to the lung in models of allergen-induced acute and chronic asthma (Banerjee et al., 2007, 2009).

Taken together, these studies in mice and men indicate that $\alpha_{4} \beta_{1}$ and $\alpha_{M} \beta_{2}$ are the major eosinophil integrins mediating cell adhesion, with $\alpha_{4} \beta_{1}$ largely responsible for arrest of blood eosinophils on VCAM-1 in vessels of the asthmatic lung, with a more minor contribution by $\alpha_{M} \beta_{2}$; whereas activated $\alpha_{M} \beta_{2}$, by interacting with periostin and possibly other ligands, is involved in subsequent eosinophil recruitment to and persistence in the ECM of the bronchi in asthma.

\section{ACTIVATION STATES OF INTEGRINS ON BLOOD AND AIRWAY EOSINOPHILS}

As purification of eosinophils leads to increased partial activation of $\beta_{1}$ integrins, assessed by mAb N29 (Johansson and Mosher, 2011); we monitor activation states of integrins on blood and airway eosinophils by processing unfractionated blood or BAL cells for flow cytometry and analyzing eosinophils, which are gated to exclude other cells, including neutrophils, monocytes, lymphocytes, and NK cells, based on CD14 and CD16 staining and scatter (Johansson et al., 2006, 2008, 2012, 2013a; Johansson and Mosher, 2011).

On the average, eosinophils in blood express the N29 and 8E3 epitopes to some degree but have no or very low expression of the HUTS-21 and 9EG7 epitopes, indicating that their $\beta_{1}$ integrins, including $\alpha_{4} \beta_{1}$, are in the intermediate-, but not high-activity, conformation (Table 1; Figure 1) (Johansson et al., 2006, 2008, 2012, 2013a; Johansson and Mosher, 2011). However, N29 and 8E3 reactivities are variable among subjects, ranging from some subjects with essentially no N29 signal and thus inactive $\beta_{1}$ integrins to some with low but detectable N29 signal (i.e., a fraction of $\beta_{1}$ integrin molecules on each cell having the intermediate-activity conformation) to some with high N29 signal (i.e., presumably most molecules having the intermediate-activity conformation) (Johansson et al., 2008, 2012; Johansson and Mosher, 2011). As a group, subjects with asthma or subjects with non-severe asthma, but not subjects with severe asthma, have a higher N29 signal than normal donors (Johansson et al., 2012). In subjects with nonsevere allergic asthma who have a dual response phenotype (i.e., they have a fall in forced expiratory volume in $1 \mathrm{~s}\left(\mathrm{FEV}_{1}\right)$ of $\geq 15 \%$ during the late-phase $3-8 \mathrm{~h}$ after whole-lung antigen challenge, in addition to the common initial early-phase fall within 15$30 \mathrm{~min}$ ), N29 reactivity was increased $48 \mathrm{~h}$ after segmental lung antigen challenge (Johansson et al., 2008). After whole-lung antigen challenge itself, which is a more major insult and a model of asthma exacerbation (Gauvreau and Evans, 2007), N29 reactivity of circulating eosinophils decreases at $8 \mathrm{~h}$ and recovers at $48 \mathrm{~h}$, indicating that cells with the highest proportion of activated $\alpha_{4} \beta_{1}$ are the ones that extravasate. We have suggested that a similar phenomenon, i.e., that the eosinophils with the most activated $\alpha_{4} \beta_{1}$ are efficiently removed, occurs continuously in severe asthma, compatible with the data that the N29 signal on circulating cells in severe asthma is not significantly higher than in normal donors (Johansson et al., 2012). Efficient removal in severe asthma may be due to greater lung endothelial VCAM-1 expression, as has been observed in bronchial biopsies of subjects with severe compared to non-severe asthma (Ramos-Barbon et al., 2010). Taken together, this information indicates that a proportion, variable among subjects, of the $\alpha_{4} \beta_{1}$ molecules on blood eosinophils are in an intermediate conformation. This proportion is higher in asthma than in healthy donors, and can increase, e.g., upon segmental antigen challenge, but can also decrease when or if the most activated cells extravasate, such as after whole-lung challenge or presumably continuously in severe asthma. 
Purified blood eosinophils are positive for N29 but not HUTS21 and 9EG7, and adhere "constitutively" to VCAM-1 in vitro in an $\alpha_{4} \beta_{1}$-dependent manner (Barthel et al., 2006a,b); compatible with a situation in which all or most of their $\alpha_{4} \beta_{1}$ molecules are in the intermediate conformation. However, purified cells are not a completely accurate reflection of eosinophils in vivo, since, as indicated above, the N29 signal increases upon cell purification (Johansson and Mosher, 2011). Thus, as eosinophils from different subjects in vivo have variable N29 reactivity, it is reasonable to assume that the capacity of eosinophils to arrest on VCAM-1 in vivo also varies among subjects.

Regarding $\beta_{2}$ integrins, eosinophils in blood (from subjects with non-severe asthma) have a low but detectable KIM-127 signal but very low reactivity with $\mathrm{mAb} 24$ and $\mathrm{CBRM} 1 / 5$, indicating that a fraction of their $\beta_{2}$ integrins, including $\alpha_{M} \beta_{2}$, is in the intermediate- (but not high-) activity conformation (Johansson et al., 2008, 2013a). In consistency with this, purified blood eosinophils do not react with CBRM1/5 and do not adhere in vitro to the $\alpha_{M} \beta_{2}$ ligands ICAM-1, fibrinogen, vitronectin, and periostin, unless IL-5 is added to stimulate the cells (Barthel et al., 2006b; Johansson et al., 2013b). However, since, as mentioned, $\alpha_{M} \beta_{2}$, in addition to $\alpha_{4} \beta_{1}$, is involved in adhesion of purified blood eosinophils from some subjects to VCAM-1 and mediates arrest to VCAM-1 under flow (Barthel et al., 2006a), a proportion of $\alpha_{M} \beta_{2}$ on blood eosinophils in the intermediate conformation is likely sufficient for $\alpha_{M} \beta_{2}$ to participate, together with $\alpha_{4} \beta_{1}$, in arrest to VCAM-1.

Eosinophils in BAL obtained after segmental antigen challenge have $\beta_{1}$ integrins in the high-activity conformation, judged by their significantly increased reactivity with HUTS-21 and 9EG7 compared to blood eosinophils (Johansson et al., 2013a). $\alpha_{M} \beta_{2}$ on such BAL eosinophils also is in a high-activity conformation, as assessed by the higher reactivity with $\mathrm{mAb} 24$ and CBRM1/5 than on blood eosinophils (Johansson et al., 2008, 2013a) and very high reactivity with KIM-127 (Johansson et al., 2013a). These flow cytometry data on eosinophils in BAL agree with the fact that purified airway eosinophils adhere to VCAM-1 to a higher degree than blood eosinophils in a process involving both $\alpha_{4} \beta_{1}$ and $\alpha_{M} \beta_{2}$, and adhere to ICAM-1, fibrinogen, and vitronectin in a $\alpha_{M} \beta_{2}$-dependent manner (Barthel et al., 2006b).

\section{ACTIVATING STIMULI}

Addition of soluble P-selectin to whole blood in vitro increases the N29 signal of blood eosinophils and their adhesion to VCAM-1 (Johansson and Mosher, 2011), thus enhancing the activation of $\alpha_{4} \beta_{1}$. Added P-selectin does not enhance the N29 signal or adhesion of purified blood eosinophils to VCAM-1, in consistency with the fact that N29 is increased and thus $\alpha_{4} \beta_{1}$ is activated during cell purification (Johansson and Mosher, 2011). We suspect that in the process of purification, contaminating platelets are activated, externalizing P-selectin and in turn activating eosinophils. In whole blood samples, eosinophil reactivity with $\mathrm{N} 29$ or $8 \mathrm{E} 3$ correlates with the amount of $\mathrm{P}$-selectin associated with the eosinophil surface in non-severe asthma (Table 2) (Johansson and Mosher, 2011), and N29 does so also in a population of subjects with asthma of varying severity (Table 2) (Johansson et al., 2012). Further, eosinophil N29 correlates with platelet-surface P-selectin expression (Johansson et al., 2012). These correlations support a scenario in which P-selectin present on the surface of activated platelets is the in vivo stimulus that by binding to eosinophils, presumably via P-selectin glycoprotein ligand-1 (PSGL-1), the eosinophil counter-receptor for P-selectin (Symon et al., 1996), triggers an intracellular signaling pathway that results in conversion of inactive to intermediate-activity $\alpha_{4} \beta_{1}$ and the stimulation of arrest on VCAM-1. As with the N29 signal, after whole-lung antigen challenge, eosinophil-bound P-selectin and eosinophil PSGL-1 decreased at $8 \mathrm{~h}$ and recovered at $48 \mathrm{~h}$ (Johansson et al., 2012), indicating that the cells with the highest PSGL-1 level and P-selectin binding, as well as highest degree of $\alpha_{4} \beta_{1}$ activation, extravasate. This situation is compatible with studies on plateletdepleted mice and mice restored with activated platelets, which showed that eosinophil recruitment after lung antigen challenge required activated platelets in a P-selectin-dependent manner (Pitchford et al., 2005).

As alluded to above, IL-5 at concentrations $\geq 1 \mathrm{ng} / \mathrm{ml}(\sim 40 \mathrm{pM})$ induces blood eosinophil reactivity with CBRM1/5 and mAb24, and adhesion to $\alpha_{M} \beta_{2}$ ligands in vitro (Zhu et al., 1999; Barthel et al., 2006a,b; Johansson and Mosher, 2011; Johansson et al., 2013b). In vivo, the KIM-127 signal of blood eosinophils was decreased in subjects with non-severe asthma after administration of anti-IL-5 mepolizumab (Table 2) (Johansson et al., 2013a), indicating that the intermediate conformation of $\beta_{2}$ integrins on

Table 2 | Evidence for eosinophil integrin activating stimuli in vivo.

\begin{tabular}{|c|c|c|c|c|}
\hline Location & Integrin & Activation state & Activating stimuli & Evidence and reference \\
\hline \multirow[t]{2}{*}{ Blood } & $\beta_{1}$ integrins & Intermediate & P-selectin & $\begin{array}{l}\text { Eosinophil-bound P-selectin correlates with N29 and } 8 \text { E3 reac- } \\
\text { tivities (Johansson and Mosher, 2011; Johansson et al., 2012), } \\
\text { platelet-surface P-selectin correlates with N29 reactivity (Johans- } \\
\text { son et al., 2012) }\end{array}$ \\
\hline & $\beta_{2}$ integrins & Intermediate & IL-5 (low concentrations) & Anti-IL-5 decreases KIM-127 reactivity (Johansson et al., 2013a) \\
\hline \multirow[t]{2}{*}{ Airway } & $\beta_{1}$ integrins & High & Unknown & Johansson et al. (2013a) \\
\hline & $\beta_{2}$ integrins & High & $\begin{array}{l}\text { Unknown } \\
\text { (IL-5 may play a role } \\
\text { but not required) }\end{array}$ & $\begin{array}{l}\text { BAL fluid IL-5 concentration correlates with mAb24 reactivity } \\
\text { (Johansson et al., 2008), but anti-IL-5 does not decrease mAb24 } \\
\text { and CBRM1/5 reactivities (Johansson et al., 2013a) }\end{array}$ \\
\hline
\end{tabular}

BAL, bronchoalveolar lavage; IL-5, interleukin-5. 
blood eosinophils is the result of exposure to IL-5 in the bone marrow and/or circulation. This IL- 5 concentration is presumably low, since it does not result in significant expression of the mAb24 and CBRM1/5 epitopes in fully activated $\alpha_{M} \beta_{2}$; and the IL- 5 concentration in the blood of subjects with asthma is only $1-10 \mathrm{pg} / \mathrm{ml}$ (0.04-0.4 pM) (Mastalerz et al., 2001; Joseph et al., 2004; Johnsson et al., 2011). Thus, KIM-127 reactivity may be a read-out of tonic in vivo IL-5 activity and may predict responsiveness to anti-IL-5.

As for airway eosinophils, we do not know what factor is responsible for their high-activity $\beta_{1}$ integrin state. We speculate that it may be the result of the eosinophils having undergone arrest, transendothelial migration, and encounters with adhesive ligands. Current thinking in the leukocyte integrin field includes the possibility that outside-in signaling following ligand-binding by integrin in the intermediate conformation brings about the final stage of activation to the high-activity conformation (Evans et al., 2009; Hogg et al., 2011). Thus, for eosinophil $\alpha_{4} \beta_{1}$, interaction with VCAM-1 during arrest and transmigration may lead to higher activation, as detected on airway eosinophils.

In our first segmental antigen challenge study, mAb24 reactivity of BAL eosinophils correlated with IL- 5 concentration in BAL fluid (Table 2) (Johansson et al., 2008), indicating that IL-5 can be an in vivo stimulus for the high-activation state of airway eosinophil $\beta_{2}$ integrins. The concentration of IL-5 in airway lining fluid in vivo is $0.1-100 \mathrm{ng} / \mathrm{ml}$ (Teran et al., 1999; Kelly et al., 2003; Johansson et al., 2008), based on the estimated 100-fold dilution during the recovery of BAL (Rennard et al., 1986; Johansson et al., 2008). However, in contrast to blood eosinophil reactivity with KIM-127; BAL eosinophil reactivities with KIM-127, mAb24, and CBRM1/5 did not decrease after anti-IL-5 administration (Table 2) (Johansson et al., 2013a). Thus, the high-activity $\alpha_{M} \beta_{2}$ state of airway eosinophils does not appear to require IL-5. Presumably, IL-3 and/or GM-CSF, which can induce adhesion to an $\alpha_{M} \beta_{2}$ ligand in vitro (Johansson et al., 2013b) and which are estimated to be present at up to $10 \mathrm{ng} / \mathrm{ml}$ in airway lining fluid (Woolley et al., 1995; Evans et al., 1996; Jarjour et al., 1997; Johansson et al., 2008), may, possibly together with other factors, be responsible for the highly activated $\alpha_{\mathrm{M}} \beta_{2}$ on airway eosinophils in vivo.

In conclusion, P-selectin or IL-5 appears responsible for the partial activation of $\alpha_{4} \beta_{1}$ or $\alpha_{M} \beta_{2}$, respectively, on blood eosinophils. These data demonstrate that different integrins on eosinophils are activated by distinct stimuli and presumably by distinct signaling pathways, which is in accordance with a recent statement that "it is clear that mechanisms of activation are not generic for all integrins" (Margadant et al., 2011). In contrast, it is uncertain which factor or combinations of factors bring about the high-activation state of $\alpha_{4} \beta_{1}$ and $\alpha_{M} \beta_{2}$ on airway eosinophils. IL-3, GM-CSF, and/or other agents, possibly in synergy, may be responsible for the high-activity $\alpha_{M} \beta_{2}$. IL-5 may play a minor, but dispensable, role. Interactions with counter-receptors or ligands during arrest, and transendothelial and continued migration may be responsible for high-activity $\alpha_{4} \beta_{1}$ and may also contribute to high-activity $\alpha_{M} \beta_{2}$.

\section{CORRELATIONS WITH EOSINOPHIL RECRUITMENT AND ASPECTS OF ASTHMA}

Although it was known that purified blood eosinophils adhere "constitutively" to VCAM-1 in vitro (Walsh et al., 1991; Weller et al., 1991; Schleimer et al., 1992; Johansson et al., 2004; Barthel et al., 2006a,b), the possibility existed that the activation state of $\alpha_{4} \beta_{1}$ in vivo would be variable and a determinant of eosinophil arrest on activated endothelium and consequently recruitment to the airway. We first tested this possibility in a double-blind placebo-controlled, two-period crossover inhaled corticosteroid (ICS) withdrawal study in subjects with non-severe asthma. N29 reactivity of blood eosinophils was found to correlate inversely with forced expiratory volume in $1 \mathrm{~s}\left(\mathrm{FEV}_{1}\right.$, as percentage of baseline) after ICS withdrawal or across all visits during the whole study (Table 3) (Johansson et al., 2006). Receiver-operator characteristic (ROC) curve analysis demonstrated that the N29 signal predicted decrease in $\mathrm{FEV}_{1}$ (Table 3) (Johansson et al., 2006). N29 correlated better with $\mathrm{FEV}_{1}$ and performed better in ROC analysis than did the established asthma biomarkers sputum eosinophil percentage and fraction of exhaled nitric oxide (FENO) (Johansson et al., 2006). Further, N29 correlated with FENO, believed to reflect airway inflammation, after ICS withdrawal (Table 3) (Johansson et al., 2006). These findings indicated that greater $\beta_{1}$ activation (i.e., higher proportion of $\beta_{1}$ integrins in the intermediate conformation vs. in the inactive conformation) on circulating eosinophils is associated with a higher degree of airway inflammation and decreased pulmonary function in non-severe asthma, presumably because subjects with a more activated $\alpha_{4} \beta_{1}$ would have a higher degree of eosinophil arrest and recruitment to the airway.

To test the hypothesis that blood eosinophil $\beta_{1}$ activation is clinically relevant in asthma in another model, we used segmental lung antigen challenge of subjects with non-severe allergic asthma. Blood eosinophil $\mathrm{N} 29$ reactivity $48 \mathrm{~h}$ after segmental challenge correlated with the late-phase fall in $\mathrm{FEV}_{1} 3-8 \mathrm{~h}$ after the whole-lung antigen challenge performed during screening (Table 3) (Johansson et al., 2008). N29 signal of airway eosinophils obtained $48 \mathrm{~h}$ after segmental challenge correlated with eosinophil percentage in BAL and was higher in dual than in single responders (Table 3) (Johansson et al., 2008). These results confirmed that degree of $\beta_{1}$ activation on blood eosinophils is associated with pulmonary function in non-severe asthma and also showed that the $\beta_{1}$ activation that occurs on airway eosinophils is associated with eosinophil recruitment. Unfortunately, blood during the screening wholelung antigen challenge part of this study was not analyzed by flow cytometry. It would be interesting to investigate more directly correlations between integrin activation during whole-lung antigen challenge and measures of eosinophil recruitment, airway inflammation, and the late-phase response, by comparing flow cytometry data and clinical parameters at different time points after whole-lung challenge.

The ICS withdrawal and antigen challenge studies were on subjects with non-severe asthma who were young adults (mean 21 years old, only one of 27 subjects older than 30) (Johansson et al., 2008). To extend the study on the relationships between $\beta_{1}$ integrin activation on blood eosinophils and pulmonary function to subjects with disease of varying severity and a greater age range, we performed an observational study in a population comprising both non-severe and severe asthma subjects with a higher mean age (34 for those with severe and 29 for those with non-severe asthma). As there was no baseline in this observational study, we examined correlations with $\mathrm{FEV}_{1}$ corrected for forced vital 
Table 3 | Correlations between eosinophil integrin activation states and eosinophil recruitment or aspects of asthma.

\begin{tabular}{|c|c|c|c|}
\hline Location & Integrin: activation state (mAb) & Correlation & Reference \\
\hline \multirow[t]{7}{*}{ Blood } & $\beta_{1}$ Integrins: intermediate (N29) & $\begin{array}{l}\text { Inverse with } \mathrm{FEV}_{1} \text { (\% of baseline) after or during ICS with- } \\
\text { drawal in non-severe asthma, predicts decrease in } \mathrm{FEV}_{1} \text { in } \\
\text { receiver-operator characteristic (ROC) curve analysis }\end{array}$ & Johansson et al. (2006) \\
\hline & & FENO after ICS withdrawal in non-severe asthma & Johansson et al. (2006) \\
\hline & & $\begin{array}{l}\text { Inverse with } \mathrm{FEV}_{1} / \mathrm{FVC} \text { in younger subjects with non-severe } \\
\text { asthma }\end{array}$ & Johansson et al. (2012) \\
\hline & & Inverse with $\mathrm{FEV}_{1} / \mathrm{FVC}$ in cluster 1 (mild atopic asthma) & Johansson et al. (2011) \\
\hline & (48 $\mathrm{h}$ after segmental antigen challenge) & $\begin{array}{l}\text { Response phenotype (increased vs. O h in dual, not single, } \\
\text { responders) }\end{array}$ & Johansson et al. (2008) \\
\hline & (48 $\mathrm{h}$ after segmental antigen challenge) & Late-phase fall in \% FEV 1 after whole-lung antigen challenge & Johansson et al. (2008) \\
\hline & $\begin{array}{l}\beta_{2} \text { Integrins: intermediate (KIM-127) (before but not } \\
\text { after anti-IL-5) }\end{array}$ & $\%$ BAL eosinophils & Johansson et al. (2013a) \\
\hline \multirow[t]{4}{*}{ Airway } & $\beta_{1}$ Integrins: intermediate-high (N29) & $\%$ BAL eosinophils & Johansson et al. (2008) \\
\hline & & $\begin{array}{l}\text { Response phenotype (higher in dual than in single respon- } \\
\text { ders) }\end{array}$ & Johansson et al. (2008) \\
\hline & $\beta_{2}$ Integrins: high (mAb24) & $\%$ BAL eosinophils & Johansson et al. (2008) \\
\hline & & Late-phase fall in \% FEV 1 after whole-lung antigen challenge & Johansson et al. (2008) \\
\hline
\end{tabular}

BAL, bronchoalveolar lavage; FEV 1 , forced expiratory volume in $1 \mathrm{~s} ;$ FVC, forced vital capacity; ICS, inhaled corticosteroid.

capacity (FVC). The correlation between $\mathrm{N} 29$ reactivity of blood eosinophils with $\mathrm{FEV}_{1} / \mathrm{FVC}$ did not reach significance in the whole asthma study population (Johansson et al., 2012). However, when subjects were stratified by severity and age, N29 correlated significantly with $\mathrm{FEV}_{1} / \mathrm{FVC}$ in those with non-severe asthma under 30 years of age (Table 3) (Johansson et al., 2012). The subjects in this study belonged to a population that had been classified using unsupervised hierarchical cluster analysis, resulting in five asthma phenotype groups (Moore et al., 2010). N29 correlated best and significantly with $\mathrm{FEV}_{1} / \mathrm{FVC}$ in cluster 1 (Johansson et al., 2011), which consists of subjects with mild atopic asthma (Moore et al., 2010).

Taking ICS withdrawal, antigen challenge, and the severe asthma studies together, it appears that greater $\beta_{1}$ integrin activation on blood eosinophils is associated with decreased pulmonary function in subjects with non-severe asthma who are relatively young, but that this association breaks down in severe asthma or in older subjects. A possible explanation for the lack of association in severe asthma is high degree of ongoing extravasation of eosinophils with the most activated $\alpha_{4} \beta_{1}$, as discussed above. An additional possible explanation is that a proportion of subjects with severe asthma do not have a predominantly eosinophilic airway inflammatory phenotype but rather a mixed eosinophilicneutrophilic or a neutrophilic phenotype (Hastie et al., 2010; Wenzel, 2012), which may contribute to the weakening of the association between eosinophil activation and lung function. Further, it is unclear why the association does not hold up in older subjects. Perhaps pulmonary function becomes less associated with eosinophil activation and recruitment as the disease evolves with time and increased age. Such a situation may be related to the observation that neutrophilic inflammation in asthma is more frequent in older adults (Wang et al., 2011; Agache et al., 2012).
Regarding $\beta_{2}$ integrins, the first antigen challenge study demonstrated that reactivity of BAL eosinophil mAb24 reactivity, like their N29 reactivity, correlated with percentage of eosinophils in BAL (Table 3) (Johansson et al., 2008). Further, the mAb24 signal of BAL eosinophils correlated with the magnitude of the late-phase response after whole-lung antigen challenge (Table 3) (Johansson et al., 2008). In the anti-IL-5 study, blood eosinophil reactivity with KIM-127 at the time of segmental challenge (before but not after anti-IL-5 administration) correlated with BAL eosinophil percentage $48 \mathrm{~h}$ later (Table 3) (Johansson et al., 2013a). Unfortunately, KIM-127 was not assayed in the earlier studies, so the repeatability of this observation is not known. However, these data indicate that the degree of (intermediate) $\beta_{2}$ integrin activation on blood eosinophils and degree of high $\beta_{2}$ activation achieved on airway eosinophils are also associated with eosinophil recruitment. These correlations offer support for the view that activation of $\beta_{2}$ integrins, presumably $\alpha_{M} \beta_{2}$, complements activation of $\alpha_{4} \beta_{1}$, in mediating eosinophil arrest and movement to the airway.

\section{CONCLUSIONS AND PERSPECTIVES}

We review information on the activation state of integrins on blood and airway eosinophils, the likely in vivo activators of eosinophil integrins, and correlations between eosinophil integrin activation and measurements of eosinophil recruitment, airway inflammation, and pulmonary function in asthma. We concentrate on studies in humans and include results of studies done on mice.

The information indicates that a proportion of $\alpha_{4} \beta_{1}$ integrin on circulating blood eosinophils is in the intermediate-activity conformation as a result of stimulation of eosinophils by Pselectin present on the surface of activated platelets binding to eosinophil PSGL-1. The proportion is variable among individuals, and thus $\alpha_{4} \beta_{1}$ activation, by conferring variable capacity to 
arrest on VCAM-1 on activated endothelium in inflamed lung, seems to be a biomarker of disease activity in younger individuals with mild asthma. A proportion of $\alpha_{M} \beta_{2}$ on blood eosinophils is also in the intermediate-activity conformation, presumably as a result of exposure to IL-5. Partially activated $\alpha_{M} \beta_{2}$ likely assists in eosinophil arrest on and extravasation from inflamed vessels, and dampening of $\alpha_{M} \beta_{2}$ activation may contribute to the therapeutic efficacy of anti-IL-5.

The classical multistep paradigm for extravasation of leukocytes (Springer, 1994), which has been applied to eosinophils (Rosenberg et al., 2007), depicts circulating leukocytes as having inactive integrins that become activated when rolling cells are exposed to chemokines associated with the surface of activated endothelium. The paradigm needs to be modified to include in vivo "pre-activation" or "priming" (Koenderman et al., 1996) mediated by P-selectin and IL-5 causing eosinophils to display integrins in partially activated conformations and leading to more efficient arrest. The modified paradigm is in accord with the conclusion that "increasing evidence suggests that subsets of circulating leukocytes express a fraction of their integrins in pre-formed intermediateaffinity states" that arrest or slow down rolling leukocytes (Alon and Dustin, 2007).

Airway eosinophils obtained by BAL $48 \mathrm{~h}$ after segmental antigen challenge have $\alpha_{4} \beta_{1}$ and $\alpha_{M} \beta_{2}$ in high-activity conformations, likely as a result of encounters with multiple factors in inflamed lung including, in the case of high-activity $\alpha_{M} \beta_{2}$, exposure to IL-3, GM-CSF, and other soluble agents, and/or interaction with ligands such as VCAM-1 (for both integrins) and periostin (for $\alpha_{M} \beta_{2}$ ). It is difficult to say much more without knowing the histories of the sampled cells as the cells responded to the challenge. Interestingly, degree of activation of both $\beta_{1}$ and $\beta_{2}$ integrins on airway eosinophils correlates with number of eosinophils found in BAL.

Observations on human blood eosinophils and genetically manipulated mice indicate that partially activated $\alpha_{4} \beta_{1}$ and $\alpha_{M} \beta_{2}$ on blood eosinophils cooperate in eosinophil arrest in vessels of inflamed bronchi and movement of eosinophils into lung tissue. $\alpha_{4} \beta_{1}$ may dominate in arrest on VCAM- 1 , and $\alpha_{M} \beta_{2}$ may dominate at the later stage by mediating extravasation and migration in the ECM. It should be stressed that some of the observations in humans are correlational in nature and have not yet been replicated by others, and a number of predictions based on the

\section{REFERENCES}

Agache, I., Akdis, C., Jutel, M., and Virchow, J. C. (2012). Untangling asthma phenotypes and endotypes. Allergy 67, 835-846.

Alon, R., and Dustin, M. L. (2007). Force as a facilitator of integrin conformational changes during leukocyte arrest on blood vessels and antigen-presenting cells. Immunity 26, 17-27.

Anderson, G. P. (2008). Endotyping asthma: new insights into key pathogenic mechanisms in a complex, heterogeneous disease. Lancet 372, 1107-1119.

observations have not been tested. For instance, identification of the vascular beds in which partial eosinophil integrin activation takes place will firm up the observations. These need not to be the beds into which eosinophils ultimately extravasate. We have suggested that eosinophils may encounter activated platelets and P-selectin (Johansson and Mosher, 2011; Johansson et al., 2012) in the pulmonary circulation, which is sampled many times per hour by all blood cells, and thus the eosinophils are primed to extravasate when coursing through the systemic circulation of the inflamed bronchus, which would happen much less often (Johansson et al., 2008). It is not known whether the diminution of $\beta_{2}$ integrin activation by anti-IL- 5 is due to neutralization of IL-5 present in low concentration in the general circulation or at higher concentrations in certain vascular beds. Longitudinal studies are needed to relate changes in integrin activation to the natural history of asthma and thus supplement correlations done on values obtained at a single time point. Such studies may give insight into why $\beta_{1}$ integrin activation on blood eosinophils correlates with pulmonary function in younger adults with nonsevere asthma but not in patients with severe disease or older patients. Murine experiments are needed to assess the arrest and extravasation of eosinophils in intact blood vessels imaged in real time and relate eosinophil behavior to integrin activation state. Similar experiments have provided important information about the behavior of platelets and neutrophils in injured or inflamed vessels. Finally, more needs to be known about roles of eosinophil integrins in modulating the movement and behavior of eosinophils in lung tissues. Such studies may reveal important roles for the five eosinophil integrins that are largely ignored in this review.

\section{ACKNOWLEDGMENTS}

This review was supported by Program Project grant P01 HL088594 from the National Institutes of Health. We are grateful to many, including William Busse, Nizar Jarjour, Loren Denlinger, Sameer Mathur, and Ronald Sorkness, without whom the studies on human subjects would not have been possible; and to them, Elizabeth Kelly, Michael Evans, and Gina Crisafi for helpful discussions and steadfast research, administrative, and statistical support and advice. We also thank Martin Humphries and Nancy Hogg for providing some of the activation-sensitive mAbs described here and for discussions on integrin conformations.

nonredundant roles for asthma development, but for optimal allergen sensitization only alpha4 is critical. Exp. Hematol. 35, 605-617.

Barthel, S. R., Annis, D. S., Mosher, D. F., and Johansson, M. W. (2006a). Differential engagement of modules 1 and 4 of vascular cell adhesion molecule-1 (CD106) by integrins alpha4betal (CD49d/29) and alphaMbeta2 (CD11b/18) of eosinophils. J. Biol. Chem. 281, 32175-32187.

Barthel, S. R., Jarjour, N. N., Mosher, D. F., and Johansson, M. W. (2006b). Dissection of the hyperadhesive phenotype of airway eosinophils in asthma. Am. J. Respir. Cell Mol. Biol. 35, 378-386.

Barthel, S. R., Johansson, M. W., McNamee, D. M., and Mosher, D. F. (2008). Roles of integrin activation in eosinophil function and the eosinophilic inflammation of asthma. J. Leukoc. Biol. 83, 1-12.

Bazzoni, G., Shih, D. T., Buck, C. A., and Hemler, M. E. (1995). Monoclonal antibody 9EG7 defines a novel beta 1 integrin epitope induced by soluble ligand and manganese, but inhibited by calcium. J. Biol. Chem. 270, 25570-25577. 
Beglova, N., Blacklow, S. C., Takagi, J., and Springer, T. A. (2002). Cysteinerich module structure reveals a fulcrum for integrin rearrangement upon activation. Nat. Struct. Biol. 9, 282-287.

Bentley, J. K., Linn, M. J., Lei, J., Comstock, A., Zhao, Y., and Hershenson, M. B. (2012). Periostin knockout mice are protected from house dust mite allergen-induced lung inflammation [abstract]. Am. J. Respir. Crit. Care Med. 185, A6873.

Blanchard, C., Mingler, M. K., McBride, M., Putnam, P. E., Collins, M. H., Chang, G., et al. (2008). Periostin facilitates eosinophil tissue infiltration in allergic lung and esophageal responses. Mucosal Immunol. 1, 289-296.

Blanchard, C., and Rothenberg, M. E. (2009). Biology of the eosinophil. Adv. Immunol. 101, 81-121.

Busse, W. W., and Lemanske, R. F. Jr. (2001). Asthma. N. Engl. J. Med. 344, 350-362.

Busse, W. W., Ring, J., Huss-Marp, J., and Kahn, J. E. (2010). A review of treatment with mepolizumab, an anti-IL-5 mAb, in hypereosinophilic syndromes and asthma. J. Allergy Clin. Immunol. 125, 803-813.

Byron, A., Humphries, J. D., Askari, J. A., Craig, S. E., Mould, A. P., and Humphries, M. J. (2009). Antiintegrin monoclonal antibodies. J. Cell Sci. 122, 4009-4011.

Coe, A. P., Askari, J. A., Kline, A. D., Robinson, M. K., Kirby, H., Stephens, P. E., et al. (2001). Generation of a minimal alpha5betal integrin-Fc fragment. J. Biol. Chem. 276, 35854-35866.

Dransfield, I., and Hogg, N. (1989). Regulated expression of $\mathrm{Mg} 2+$ binding epitope on leukocyte integrin alpha subunits. EMBO J. 8, 3759-3765.

Evans, D. J., Barnes, P. J., Spaethe, S. M., van Alstyne, E. L., Mitchell, M. I., and O'Connor, B. J. (1996). Effect of a leukotriene B4 receptor antagonist, LY293111, on allergen induced responses in asthma. Thorax 51, 1178-1184.

Evans, R., Patzak, I., Svensson, L., De Filippo, K., Jones, K., McDowall, A., et al. (2009). Integrins in immunity. J. Cell Sci. 122, 215-225.

Flood-Page, P., Menzies-Gow, A., Phipps, S., Ying, S., Wangoo, A., Ludwig, M. S., et al. (2003). AntiIL-5 treatment reduces deposition of ECM proteins in the bronchial subepithelial basement membrane of mild atopic asthmatics. J. Clin. Invest. 112, 1029-1036.
Gauvreau, G. M., and Evans, M. Y. (2007). Allergen inhalation challenge: a human model of asthma exacerbation. Contrib. Microbiol. 14, 21-32.

Haldar, P., Brightling, C. E., Hargadon, B., Gupta, S., Monteiro, W., Sousa, A., et al. (2009). Mepolizumab and exacerbations of refractory eosinophilic asthma. N. Engl. J. Med. 360, 973-984.

Haldar, P., Pavord, I. D., Shaw, D. E., Berry, M. A., Thomas, M., Brightling, C. E., et al. (2008). Cluster analysis and clinical asthma phenotypes. Am. J. Respir. Crit. Care Med. 178, 218-224.

Harburger, D. S., and Calderwood, D. A. (2009). Integrin signalling at a glance. J. Cell Sci. 122, 159-163.

Hastie, A. T., Moore, W. C., Meyers, D. A., Vestal, P. L., Li, H., Peters, S. P., et al. (2010). Analyses of asthma severity phenotypes and inflammatory proteins in subjects stratified by sputum granulocytes. J. Allergy Clin. Immunol. 125, 1028-1036.

Hayashi, N., Yoshimoto, T., Izuhara, K., Matsui, K., Tanaka, T., and Nakanishi, K. (2007). T helper 1 cells stimulated with ovalbumin and IL-18 induce airway hyperresponsiveness and lung fibrosis by IFN-gamma and IL-13 production. Proc. Natl. Acad. Sci. U.S.A. 104, 14765-14770.

Hogan, S. P., Rosenberg, H. F., Moqbel, R., Phipps, S., Foster, P. S., Lacy, P., et al. (2008). Eosinophils: biological properties and role in health and disease. Clin. Exp. Allergy 38, 709-750.

Hogg, N., Patzak, I., and Willenbrock, F. (2011). The insider's guide to leukocyte integrin signalling and function. Nat. Rev. Immunol. 11, 416-426.

Humphries, J. D., Byron, A., and Humphries, M. J. (2006). Integrin ligands at a glance. J. Cell Sci. 119, 3901-3903.

Humphries, M. J. (2004). Monoclonal antibodies as probes of integrin priming and activation. Biochem. Soc. Trans. 32, 407-411.

Huttenlocher, A., Ginsberg, M. H., and Horwitz, A. F. (1996). Modulation of cell migration by integrin-mediated cytoskeletal linkages and ligandbinding affinity. J. Cell Biol. 134, 1551-1562.

Hynes, R. O. (1987). Integrins: a family of cell surface receptors. Cell 48 , 549-554.

Jarjour, N. N., Calhoun, W. J., Kelly, E. A., Gleich, G. J., Schwartz, L. B., and Busse, W. W. (1997). The immediate and late allergic response to segmental bronchopulmonary provocation in asthma. Am. J. Respir. Crit. Care Med. 155, 1515-1521.

Johansson, M. W., Barthel, S. R., Swenson, C. A., Evans, M. D., Jarjour N. N., Mosher, D. F., et al. (2006) Eosinophil beta(1) integrin activation state correlates with asthma activity in a blind study of inhaled corticosteroid withdrawal. J. Allergy Clin. Immunol. 117, 1502-1504.

Johansson, M. W., Gunderson, K. A., Kelly, E. A. B., Denlinger, L. C., Jarjour, N. N., and Mosher, D. F. (2013a). Anti-IL-5 attenuates activation and surface density of $\beta 2$ integrins on circulating eosinophils after segmental antigen challenge. Clin. Exp. Allergy 43, 292-303.

Johansson, M. W., Annis, D. S., and Mosher, D. F. (2013b). AlphaMbeta2 integrin-mediated adhesion and motility of interleukin-5-stimulated eosinophils on periostin. Am. J. Respir. Cell Mol. Biol. (in press) Available from: http://ajrcmb atsjournals.org/content/early/recent as doi:10.1165/rcmb.2012-0150OC

Johansson, M. W., Han, S. T., Gunderson, K. A., Busse, W. W., Jarjour, N. N., and Mosher, D. F. (2012). Platelet activation, $\mathrm{P}$-selectin, and eosinophil betal-integrin activation in asthma. Am. J. Respir. Crit. Care Med. 185 498-507.

Johansson, M. W., Han, S.-T., Gunderson, K. A., Montgomery, R. R., Busse, W. W., Jarjour, N. N., et al. (2011). Platelet activation, P-selectin mobilization, and eosinophil betal integrin activation occur in asthma and are associated with clinical phenotypes [abstract]. Am. J. Respir. Crit. Care Med. 183, A4335.

Johansson, M. W., Kelly, E. A., Busse, W. W., Jarjour, N. N., and Mosher, D. F. (2008). Up-regulation and activation of eosinophil integrins in blood and airway after segmental lung antigen challenge. J. Immunol. 180, 7622-7635.

Johansson, M. W., Lye, M. H., Barthel, S. R., Duffy, A. K., Annis, D. S., and Mosher, D. F. (2004). Eosinophils adhere to vascular cell adhesion molecule-1 via podosomes. Am. J. Respir. Cell Mol. Biol. 31, 413-422.

Johansson, M. W., and Mosher, D. F (2011). Activation of \{beta\}1 integrins on blood eosinophils by $\mathrm{P}$ selectin. Am. J. Respir. Cell Mol. Biol. 45, 889-897.

Johnsson, M., Bove, M., Bergquist, H., Olsson, M., Fornwall, S., Hassel, K., et al. (2011). Distinctive blood eosinophilic phenotypes and cytokine patterns in eosinophilic esophagitis, inflammatory bowel disease and airway allergy. J. Innate Immun. 3, 594-604.

Joseph, J., Benedict, S., Safa, W., and Joseph, M. (2004). Serum interleukin-5 levels are elevated in mild and moderate persistent asthma irrespective of regular inhaled glucocorticoid therapy. BMC Pulm. Med. 4:2. doi:10.1186/1471-2466-4-2

Kay, A. B., Phipps, S., and Robinson, D. S. (2004). A role for eosinophils in airway remodelling in asthma. Trends Immunol. 25, 477-482.

Kelly, E. A. B., Busse, W. W., and Jarjour, N. N. (2003). A comparison of the airway response to segmental antigen bronchoprovocation in atopic asthma and allergic rhinitis. J. Allergy Clin. Immunol. 111, 79-86.

Kita, H. (2011). Eosinophils: multifaceted biological properties and roles in health and disease. Immunol. Rev. 242, 161-177.

Koenderman, L., van der Bruggen, T., Schweizer, R. C., Warringa, R. A., Coffer, P., Caldenhoven, E., et al. (1996). Eosinophil priming by cytokines: from cellular signal to in vivo modulation. Eur. Respir. J. Suppl. 22, 119s-125s.

Lee, J. J., Jacobsen, E. A., McGarry, M. P., Schleimer, R. P., and Lee, N. A. (2010). Eosinophils in health and disease: the LIAR hypothesis. Clin. Exp. Allergy 40, 563-575.

Leitinger, B., and Hogg, N. (2000). Effects of I domain deletion on the function of the beta 2 integrin lymphocyte function-associated antigen-1. Mol. Biol. Cell 11, 677-690.

Lenter, M., Uhlig, H., Hamann, A., Jeno, P., Imhof, B., and Vestweber, D. (1993). A monoclonal antibody against an activation epitope on mouse integrin chain beta 1 blocks adhesion of lymphocytes to the endothelial integrin alpha 6 beta 1. Proc. Natl. Acad. Sci. U.S.A. 90, 9051-9055.

Lotvall, J., Akdis, C. A., Bacharier, L. B., Bjermer, L., Casale, T. B., Custovic, A., et al. (2011). Asthma endotypes: a new approach to classification of disease entities within the asthma syndrome. J. Allergy Clin. Immunol. 127, 355-360.

Lu, C., Shimaoka, M., Zang, Q., Takagi, J., and Springer, T. A. (2001). Locking in alternate conformations of the integrin alphaLbeta2 I domain with disulfide bonds reveals functional relationships among integrin domains. Proc. Natl. Acad. Sci. U.S.A. 98, 2393-2398.

Luo, B. H., Carman, C. V., and Springer, T. A. (2007). Structural 
basis of integrin regulation and signaling. Annu. Rev. Immunol. 25, 619-647.

Luo, B. H., and Springer, T. A. (2006). Integrin structures and conformational signaling. Curr. Opin. Cell Biol. 18, 579-586.

Luque, A., Gomez, M., Puzon, W., Takada, Y., Sanchez-Madrid, F., and Cabanas, C. (1996). Activated conformations of very late activation integrins detected by a group of antibodies (HUTS) specific for a novel regulatory region (355-425) of the common beta 1 chain. J. Biol. Chem. 271, 11067-11075.

Margadant, C., Monsuur, H. N., Norman, J. C., and Sonnenberg, A. (2011). Mechanisms of integrin activation and trafficking. Curr. Opin. Cell Biol. 23, 607-614.

Mastalerz, L., Sanak, M., and Szczeklik, A. (2001). Serum interleukin-5 in aspirin-induced asthma. Clin. Exp. Allergy 31, 1036-1040.

Masuoka, M., Shiraishi, H., Ohta, S., Suzuki, S., Arima, K., Aoki, S., et al. (2012). Periostin promotes chronic allergic inflammation in response to Th2 cytokines. J. Clin. Invest. 122, 2590-2600.

Moore, W. C., Meyers, D. A., Wenzel, S. E., Teague, W. G., Li, H., Li, X., et al. (2010). Identification of asthma phenotypes using cluster analysis in the Severe Asthma Research Program. Am. J. Respir. Crit. Care Med. 181, 315-323.

Mould, A. P., Travis, M. A., Barton, S. J., Hamilton, J. A., Askari, J. A., Craig, S. E., et al. (2005). Evidence that monoclonal antibodies directed against the integrin beta subunit plexin/semaphorin/integrin domain stimulate function by inducing receptor extension. J. Biol. Chem. 280, 4238-4246.

Nair, P., Pizzichini, M. M., Kjarsgaard, M., Inman, M. D., Efthimiadis, A., Pizzichini, E., et al. (2009). Mepolizumab for prednisonedependent asthma with sputum eosinophilia. N. Engl. J. Med. 360, 985-993.

Ni, H., Li, A., Simonsen, N., and Wilkins, J. A. (1998). Integrin activation by dithiothreitol or $\mathrm{Mn} 2+$ induces a ligand-occupied conformation and exposure of a novel NH2-terminal regulatory site on the betal integrin chain. J. Biol. Chem. 273, 7981-7987.

Oxvig, C., Lu, C., and Springer, T. A. (1999). Conformational changes in tertiary structure near the ligand binding site of an integrin I domain. Proc. Natl. Acad. Sci. U.S.A. 96, 2215-2220.
Palecek, S. P., Loftus, J. C., Ginsberg, M. H., Lauffenburger, D. A., and Horwitz, A. F. (1997). Integrinligand binding properties govern cell migration speed through cellsubstratum adhesiveness. Nature 385, 537-540.

Pavord, I. D., Korn, S., Howarth, P., Bleecker, E. R., Buhl, R., Keene, O. N., et al. (2012). Mepolizumab for severe eosinophilic asthma (DREAM): a multicentre, doubleblind, placebo-controlled trial. Lancet 380, 651-659.

Pitchford, S. C., Momi, S., Giannini, S., Casali, L., Spina, D., Page, C. P., et al. (2005). Platelet P-selectin is required for pulmonary eosinophil and lymphocyte recruitment in a murine model of allergic inflammation. Blood 105, 2074-2081.

Ramos-Barbon, D., Fraga-Iriso, R., Brienza, N. S., Montero-Martinez, C., Verea-Hernando, H., Olivenstein, R., et al. (2010). T Cells localize with proliferating smooth muscle alphaactin+ cell compartments in asthma. Am. J. Respir. Crit. Care Med. 182, 317-324.

Rennard, S. I., Basset, G., Lecossier, D., O’Donnell, K. M., Pinkston, P., Martin, P. G., et al. (1986). Estimation of volume of epithelial lining fluid recovered by lavage using urea as marker of dilution. J. Appl. Physiol. 60, 532-538.

Robinson, D. S. (2013). Mepolizumab treatment for asthma. Expert Opin. Biol. Ther. 13, 295-302.

Robinson, M. K., Andrew, D., Rosen, H., Brown, D., Ortlepp, S., Stephens, P., et al. (1992). Antibody against the Leu-CAM beta-chain (CD18) promotes both LFA-1- and CR3dependent adhesion events. J. Immunol. 148, 1080-1085.

Rosenberg, H. F., Dyer, K. D., and Foster, P. S. (2013). Eosinophils: changing perspectives in health and disease. Nat. Rev. Immunol. 13, 9-22.

Rosenberg, H. F., Phipps, S., and Foster, P. S. (2007). Eosinophil trafficking in allergy and asthma. J. Allergy Clin. Immunol. 119, 1303-1310.

Ruoslahti, E. (1991). Integrins. J. Clin. Invest. 87, 1-5.

Schleimer, R. P., Sterbinsky, S. A., Kaiser, J., Bickel, C. A., Klunk, D. A., Tomioka, K., et al. (1992). IL 4 induces adherence of human eosinophils and basophils but not neutrophils to endothelium. Association with expression of VCAM-1. J. Immunol. 148, 1086-1092.

Scott, K. A., and Wardlaw, A. J. (2006). Eosinophilic airway disorders. Semin. Respir. Crit. Care Med. 27, 128-133.
Shattil, S. J., Kim, C., and Ginsberg, M. H. (2010). The final steps of integrin activation: the end game. Nat. Rev. Mol. Cell Biol. 11, 288-300.

Simpson, J. L., Scott, R., Boyle, M. J., and Gibson, P. G. (2006). Inflammatory subtypes in asthma: assessment and identification using induced sputum. Respirology 11, 54-61.

Siroux, V., Basagana, X., Boudier, A., Pin, I., Garcia-Aymerich, J., Vesin, A., et al. (2011). Identifying adult asthma phenotypes using a clustering approach. Eur. Respir. J. 38, 310-317.

Springer, T. A. (1994). Traffic signals for lymphocyte recirculation and leukocyte emigration: the multistep paradigm. Cell 76, 301-314.

Symon, F. A., Lawrence, M. B., Williamson, M. L., Walsh, G. M., Watson, S. R., and Wardlaw, A. J. (1996). Functional and structural characterization of the eosinophil P-selectin ligand. J. Immunol. 157, 1711-1719.

Takayama, G., Arima, K., Kanaji, T. Toda, S., Tanaka, H., Shoji, S., et al. (2006). Periostin: a novel component of subepithelial fibrosis of bronchial asthma downstream of IL4 and IL-13 signals. J. Allergy Clin. Immunol. 118, 98-104.

Teran, L. M., Carroll, M. P., Shute, J. K., and Holgate, S. T. (1999). Interleukin 5 release into asthmatic airways 4 and 24 hours after endobronchial allergen challenge: its relationship with eosinophil recruitment. Cytokine 11, 518-522.

Walsh, G. M., Mermod, J. J., Hartnell, A., Kay, A. B., and Wardlaw, A. J. (1991). Human eosinophil, but not neutrophil, adherence to IL-1stimulated human umbilical vascular endothelial cells is alpha 4 beta 1 (very late antigen-4) dependent. J. Immunol. 146, 3419-3423.

Wang, F., He, X. Y., Baines, K. J., Gunawardhana, L. P., Simpson, J. L., Li, F., et al. (2011). Different inflammatory phenotypes in adults and children with acute asthma. Eur. Respir. J. 38, 567-574.

Weller, P. F., Rand, T. H., Goelz, S. E., Chi-Rosso, G., and Lobb, R. R. (1991). Human eosinophil adherence to vascular endothelium mediated by binding to vascular cell adhesion molecule 1 and endothelial leukocyte adhesion molecule 1. Proc. Natl. Acad. Sci. U.S.A. 88, 7430-7433.

Wenzel, S. E. (2012). Asthma phenotypes: the evolution from clinical to molecular approaches. Nat. Med. 18, 716-725.

Wilkins, J. A., Li, A., Ni, H., Stupack, D. G., and Shen, C. (1996). Control of betal integrin function. Localization of stimulatory epitopes. J. Biol. Chem. 271, 3046-3051.

Wills-Karp, M., and Karp, C. L. (2004). Eosinophils in asthma: remodeling a tangled tale. Science 305, 1726-1729.

Woodruff, P. G., Boushey, H. A., Dolganov, G. M., Barker, C. S., Yang, Y. H., Donnelly, S., et al. (2007). Genome-wide profiling identifies epithelial cell genes associated with asthma and with treatment response to corticosteroids. Proc. Natl. Acad. Sci. U.S.A. 104, 15858-15863.

Woodruff, P. G., Modrek, B., Choy, D. F., Jia, G., Abbas, A. R., Ellwanger, A., et al. (2009). T-helper type 2-driven inflammation defines major subphenotypes of asthma. Am. J. Respir. Crit. Care Med. 180, 388-395.

Woolley, K. L., Adelroth, E., Woolley, M. J., Ellis, R., Jordana, M., and O'Byrne, P. M. (1995). Effects of allergen challenge on eosinophils, eosinophil cationic protein, and granulocyte macrophage colony-stimulating factor in mild asthma. Am. J. Respir. Crit. Care Med. 151, 1915-1924.

Yuyama, N., Davies, D. E., Akaiwa, M., Matsui, K., Hamasaki, Y., Suminami, Y., et al. (2002). Analysis of novel disease-related genes in bronchial asthma. Cytokine 19, 287-296.

Zhu, X., Munoz, N. M., Kim, K. P., Sano, H., Cho, W., and Leff, A. R. (1999). Cytosolic phospholipase A2 activation is essential for beta 1 and beta 2 integrin-dependent adhesion of human eosinophils. J. Immunol. 163, 3423-3429.

Conflict of Interest Statement: The authors declare that the research was conducted in the absence of any commercial or financial relationships that could be construed as a potential conflict of interest.

Received: 15 February 2013; accepted: 11 March 2013; published online: 01 April 2013.

Citation: Johansson MW and Mosher DF (2013) Integrin activation states and eosinophil recruitment in asthma. Front. Pharmacol. 4:33. doi: 10.3389/fphar.2013.00033

This article was submitted to Frontiers in Experimental Pharmacology and Drug Discovery, a specialty of Frontiers in Pharmacology.

Copyright (c) 2013 Johansson and Mosher. This is an open-access article distributed under the terms of the Creative Commons Attribution License, which permits use, distribution and reproduction in other forums, provided the original authors and source are credited and subject to any copyright notices concerning any third-party graphics etc. 